\title{
The Intention Research on Sports Leisure Behavior of Wuhan Citizens
}

\author{
Yuguang Zhu \\ Dance Performance Department of Art and Design College \\ Wuhan Technology and Business University \\ Wuhan, China \\ Email: 59529232@qq.com
}

\begin{abstract}
In five thousand years of history, the society is constantly making progress. Particularly, after entering 21st century, economy is dramatically improving, and incomes and spare time are constantly improving, and people's thought is improved to a realm and requirements of life quality are also improved. People look for leisure activities to realize self-development and release pressure, while satisfying material demands. Since then, SL is developed and favored by people. Developed leisure entertainment in Wuhan is powerful, its development is not ideal. Therefore, this thesis tries to discuss influence factors of urban residents SL behavior intention, reveals SL behavior intention and promotes SL development in Wuhan.
\end{abstract}

\section{Keywords: SL; Wuhan citizens; behavior intention}

\section{RESEARCH BACKGROUND AND SIGNIFICANCE}

A. Research Background: 1. SL (Sports Leisure): Various grand meetings are held in China, so it greatly stimulates people's yearning for SL. Particularly, August $8^{\text {th }}$ of every year has been set up as the "Fitness Day" since 2009 by the State Council after the 2008 Beijing Olympic Games. SL in big-middle cities becomes a fashion to improve life quality in the new era. Today's society is rapidly changing, so basic necessities of life have a problem, resulting in intangible pressure in constant development. SL is necessary to relieve the pressure. 2. Leisure time: China's five-day working system was implemented in 1995. Moreover, there are more minor vacations. It is convenient for trip in the National Day and the Spring Festival and it is a good chance for days off in the Dragon Festival and the Mid-Autumn Festival, promoting people's demands for SL.

B. Research Significance: 1. Theoretical significance: SL is gradually valuing. Wuhan has developed entertainment industry, but development of SL is not ideal, because development entity of SL has unclear behavioral demand cognition. This thesis analyzes Wuhan citizens' influence factors of SL behavior intention to embody their types and the difference, reveals its behavior feature intention and provides theoretical support for practice. 2. Practice significance: By studying behavior characters, it is good for analyzing SL behavior demands of Wuhan citizens, increasing SL market developers' comprehension on market demands, decision-making and satisfactory leisure projects, and providing reference suggestion on operation management to promote its development.
C. Domestic and Overseas Research Status: 1. Overseas research status: In $20^{\text {th }}$ century, SL has been valuing and developing to a high degree. SL consumption has a high proportion. SL has been a pillar industry in national economy. Aristotle advocated the earliest leisure theory: mankind for peak and work for leisure, leisure is the purpose of all human activities and the result of all actions. 2. Domestic research status: Bian Ying and Liao Yan (2014) showed that social development needs the equilibrium of substantial and spiritual civilization. SL is good for constructing spiritual civilization and promoting development of human and society for a well-off society ${ }^{[1]}$. Based on life circle, Song Yinan (2014) analyzed life circles of everyday, weekends and holidays. Shenyang sports behavior features show that sport equipment and green places are main sites, while they tend to gym on weekends, showing the reviving of consumption behaviors. [2] Gao Hongyan and Jiang Xiaoping(2014) based on Zhejiang citizens analyzed demographic characteristics of sports opportunity recognition, used empirical study to show that social population situation as objective factors greatly affects urban residents' SL cognition ${ }^{[3]}$. Shao Xuemei (2013) showed the further expansion of SL mode and advocated new SL mode based on SL feature study in intermediate stratum. ${ }^{[4]}$.

\section{RELEVANT CONCEPTS AND THEORETICAL BASIS}

A. Relevant Concepts: 1. Sports leisure: SL refers to physical exercise activity, emphasizing on relaxation and pleasure. SL has no high requirements for technologies and site facilities suitable for extensive people of all ages and emphasizes on activity freedom and pleasure. Sports leisure is a tendency in today's society. ${ }^{[6-8]}$.

B. Theoretical Basis: 1. Theory of planned behavior: Theory of planned behavior (TPB) was proposed by Icek Ajzen $(1988,1991)$ as the successor of Theory of Reasoned Action (TRA) by Ajzen and Fishbein (1975, 1980). TPB helps us to comprehend how to change behavior mode and shows that human behavior is the deliberate result of plans ${ }^{[9]}$. 2. Market Segmentation: Market Segmentation refers to divide the product market into several consumer groups by marketers on the basis of consumer demands and desire, purchasing behavior and habits. Each consumer group is the market segmentation, showing the consumer group with similar demand tendency [10] 


\section{QUESTIONNAIRE DESIGN AND DEMOGRAPHICS}

\section{A. Questionnaire Design}

1). Questionnaire method: Questionnaire method is also called as the "written investigation survey method" to indirectly collect research materials. This study analyzes the influence degree of gender, age, cultural degree, occupation, family structure and monthly incomes on their SL behavior intention. This study regards Wuhan citizens as research objects to grant 200 questionnaires and recycle all of them, excluding 6 invalid questionnaires for incomplete information, obtaining 194 effective questionnaires. The investigation was conducted in 2014 through fixed-point investigation and random investigation in Hankou River Beach, Hongshan Square and Zhongshan Park by granting and recycling on the spot.

2). Reliability analysis: Reliability analysis effectively measures whether integrated evaluation system has stability and reliability. In practice, reliability test is present in coefficient of association with test-retest, duplicate, split-half and Cronbach and scorer.

\section{B. Demographics}

1. Gender: Men and women have a difference in personality, emotions, lifestyles and economic ability. This study investigated 194 people, including 92 men and 102 women, accounting for $47.4 \%$ and $52.6 \%$, respectively, more women than men. 2. Age: 81 respondents are 17-24 years old, accounting for $41.8 \%, 71$ respondents are $25-35$ years old, accounting for $36.6 \%, 23$ respondents are $36-50$ years old, accounting for $11.9 \%, 9$ respondents are 51-60 years old, occupying $4.6 \%$, and students below 16 and old people above 60 had the proportion of $3.6 \%$ and $1.5 \%$, respectively. Residents of all ages have a great difference in demand and activity items of SL. 3. Education: 83 respondents, 11 respondents, 23 respondents, 34 respondents, and 43 respondents are undergraduates, postgraduates, junior high school students, high school students and junior college students, respectively, accounting for $42.8 \%, 5.7 \%, 11.9 \%, 17 . \%$ and $22.2 \%$, respectively. It shows the cultural quality of Wuhan residents. 4. Occupation: There are a total of 8 occupations and others, workers, students, farmers, teachers, civil servants, professionals, managers, retires and others account for $29.4 \%, 18.6 \%, 3.1 \%, 4.6 \%, 0.5 \%, 16 \%, 6.2 \%$, $1.5 \%$, and $20.1 \%$, respectively. Different occupations have the diverse lifestyles, leisure time and SL motivation, so as to affect its implement and types of activities. 5. Family structure: 65 single people, couples, a family of three, two generations, three generations and 7 people with others account for $33.5 \%, 11.9 \%, 28.9 \%, 8.8 \%, 33.4 \%$ and $3.6 \%$, respectively. In general, single is seldom affected by the family. Other family structures more or less will be affected, especially for a family of three. 6. Monthly incomes per capita: People with incomes $\geq 3000$ occupy $54.6 \%$. People with incomes $\leq 499$, 500-999, 1000-2999 and 2000-2999 include 8, 5, 33 and 42, accounting for $4.15 \%, 2.6 \%, 17 \%$ and $21.6 \%$, respectively.

\section{SL BEHAVIOR FEATURE ANALYSis OF WUHAN CITIZENS}

A. Reliability Analysis of Wuhan Citizens' Behavior Intention: Before analyzing the questionnaire, reliability analysis is conducted. This study applies Cronbach's Alpha reliability method. The coefficient $>0.6$ shows higher reliability; $0.7<$ coefficient $<0.8$ shows considerably high reliability; $0.8<$ coefficient $<0.9$ shows good scale reliability.

B. Self-attitude of SL: 4 people disagree agree with meeting new friends $(2.1 \%) .41$ people think that it is general $(21.1 \%), 86$ people agree with it $(44.3 \%)$, and 63 people strongly agree with it $(32.5 \%) .3$ people strongly disagree with gathering with friends, accounting for $1.5 \%$. 38 people think that it is general, occupying 19.6\%, 90 people agree with it, occupying $46.4 \%$ and 63 people strong agree with it, accounting for $32.5 \%$. 13 people think health promotion and physical ability are general, accounting for $6.7 \%$. 75 people agree with it, accounting for $38.7 \%, 54.6 \%$ of people strong agree with it (106). $1.5 \%$ of people strong disagree with being nervous and stimulative (3), $23.7 \%$ of people disagree with it $(23.7 \%)$, $43.8 \%$ of people think it is general (85), $20.6 \%$ of people agree with it and $10.3 \%$ of people strong agree with it (20). $4.1 \%$ of people disagree with elegant enjoyment (8), $30.4 \%$ of people think it is general (59), $40.7 \%$ of people agree with it (79), and $24.7 \%$ of people strongly agree with it(48). $0.5 \%$ of people disagree with relaxing and relieving pressure (1), $7.2 \%$ of people think it is general (14), $48.8 \%$ of people agree with it (94), and $43.8 \%$ of people strong agree with it (85). $3.6 \%$ of people strongly disagree with wasting time and energy (7), $36.1 \%$ of people disagree with it (70), 39.7\% of people think it is general (77), $14.9 \%$ of people agree with it (29) and $5.7 \%$ of people strong agree with it (11). Based on the entire analysis, it shows majorities of samples maintain the neutral and positive direction to influence factors of Wuhan citizens' SL.

C. Other-attitude: $0.5 \%$ of people strongly disagree and disagree with family support (1), respectively. $17.5 \%$ of people think it is general (34), 53.6\% of people agree with it (104) and $29.9 \%$ of people strongly agree with it (58). $1 \%$ of people strongly disagree with support of colleagues and classmates (2), and $0.5 \%$ of people disagree with it (1). $16.5 \%$ of people think it is general (32), $52.6 \%$ of people agree with it (102), and $27.3 \%$ of people strong agree with it (53). $1.5 \%$ of people disagree with friend support, $16.5 \%$ of people think it is general (32), $54.6 \%$ of people agree with it (106), and $27.3 \%$ of people strongly agree with it (53). $1 \%$ of people disagree with support of acquaintance (2), $28.4 \%$ of people think it is general (55), $44.8 \%$ of people agree with it $(87 \%)$, and $25.8 \%$ of people strongly agree with it (50). $0.5 \%$ of people strongly disagree with competent department (1), $0.5 \%$ of people disagree with it (1), $27.3 \%$ of people think it is general(53), $42.3 \%$ of people agree with it(82), and $29.4 \%$ of people strongly agree with it. $0.5 \%$ of people strongly disagree with support of managers (1), $1.5 \%$ of people disagree with it (3), $17.5 \%$ of people think it is general (34), $42.3 \%$ of people agree with it (82), and $38.1 \%$ of people strongly agree with it (74). $0.5 \%$ of people strongly disagree with amateur support (1), $1 \%$ of people disagree with it (2), $14.9 \%$ 
of people think it is general (29), $52.6 \%$ of people agree with it (102), and $30.9 \%$ of people strongly agree with it (60). Based on the entire analysis, it shows that majorities of samples maintain the neutral and positive direction to influence factors of Wuhan citizens' SL.

D. Condition Preparation: $0.5 \%$ of people strongly disagree with sufficient economy (1), $6.2 \%$ of people disagree with it (12), $42.8 \%$ of people think it is general(83), $41.2 \%$ of people agree with it (80), and $9.3 \%$ of people strong agree with it (18). $0.5 \%$ of people strongly agree with it (1), $8.2 \%$ of people disagree with it (16), $45.4 \%$ of people think it is general (88), $33.5 \%$ of people agree with it (65), $12.4 \%$ of people strongly agree with it (24). $0.5 \%$ of people strongly disagree with sufficient physical (1), $6.2 \%$ of people disagree with it (12), $38.1 \%$ of people think it is general (74), $41.2 \%$ of people agree with it (80), and $13.9 \%$ of people strongly agree with it (27). $0.5 \%$ of people strongly disagree with regular organization (1), 19.6\% of people disagree (38), $49 \%$ of people think it is general (95), and $25.3 \%$ of people agree (49), and $5.7 \%$ of people strongly agree (11). $12.4 \%$ of people disagree with information acquisition (24), 54.1\% of people think it is general (105), $28.4 \%$ of people agree (55), and $5.2 \%$ of people strongly agree (10). $12.4 \%$ of people disagree with sufficient convenience (24), $45.4 \%$ of people think it is general (88), $32.5 \%$ of people agree (63), and $9.8 \%$ of people strongly agree (19). $1 \%$ of people strongly disagree with sufficient site facilities (2), $11.9 \%$ of people disagree (23), 39.2\% of people think it is general (76), 33.5\% of people agree (65), and $14.4 \%$ of people strongly agree (28). Based on the entire analysis, it shows that majorities of samples maintain the neutral and positive direction to influence factors of Wuhan citizens' SL.

E. Common sensation: In common sensation, most of people remain neutral. $53.61 \%, 29.38 \%, 6.19 \%, 9.78 \%$ and $1.03 \%$ of people think it is general, satisfactory, extremely satisfactory, dissatisfactory and extremely satisfactory, respectively. According to statistics, citizens have a good feeling on SL. It is good for developing and publicizing its SL and promoting its development.

\section{SL INTENTION OF WUHAN CITIZENS}

A. SL Intention: The investigation shows more than half of people start or continues participating SL activities. $13.4 \%, 30.14 \%, 2.58 \%$ and $0.52 \%$ of people are very willing, neutral, unwilling and very unwilling, respectively. Data show that Wuhan citizens have certain understanding on SL and comprehend its importance, showing positive attitude towards it.

B. Style Orientation: This problem applies the multiple response analysis. The investigation result shows that entertainment, strength, sports skill, adventure challenge, game competition, and healthcare are selected for 52 times, 32 times, 62 times, 22 times, 25 times, and 68 times, respectively, with the response percent of $19.9 \%$, $12.3 \%, 23.8 \%, 8.4 \%, 9.6 \%$ and $26.1 \%$, respectively, and with the case percent of $26.8 \%, 12.3 \%, 32.00 \%, 11.30 \%$, $12.9 \%$, and $35.1 \%$, respectively. Different citizens will have diverse opinions, but attitude towards each style is different. They are willing to select relaxed items, but they don't notice adventure challenge and game competition.

\section{Professional Service Intention: Multiple} response analysis method is used for analysis. The investigation results show that $82,52,54,62,75$ and 17 people select technical guide, ladder player, nutrition consulting, project selection guide, sports enthusiasts and doesn't matter, respectively, with the response percent of $24 \%, 15.2 \%, 15.8 \%, 18.1 \%, 21.9 \%$ and $5 \%$, respectively, with the case percent of $42.3 \%, 26.8 \%, 27.8 \%, 18.1 \%, 38.7 \%$ and $8.8 \%$, respectively. Different citizens have diverse demands for major services. Doesn't matter is a few. It is necessary to develop features to attract consumers.

D. Attention on Site Services: $35.57 \%$, 29.9\%, $14.95 \%, 11.34 \%$ and $8.25 \%$ of people value environment, service quality, technology, price and don't matter, respectively. It is necessary to fully reinforce site environment and service quality of SL to meet consumers' demands and promote development of SL site.

E. Entertainment Attitude: $64.95 \%$ citizens think entertainment attitude is general, $7.73 \%$ of people really like, $24.23 \%$ of people like it, $3.09 \%$ of people dislike it, and no one hates it. Data shows that majorities of citizens remain neutral, but also most no one hates it, showing that citizens prefer to accept, so it is necessary to reinforce development and innovation of SL entertainment to meet citizens' demands and promote its development.

F. Attention on site catering: Citizens' degree on features, nutrition and taste occupies $22.16 \%, 27.84 \%$ and $29.9 \%$. The degree on the grade is only $5.15 \%$. Never mind occupies $14.95 \%$.

\section{RESEARCH CONCLUSIONS AND SUGGESTION}

A. Research Conclusions: This thesis used questionnaire and reliability analysis to study Wuhan citizens' sports leisure. The reliability analysis shows the good consistency in each scale. Scale design is reasonable. According to the frequency in SL, entire feeling in SL or willing to start or continue SL, substance demands can't meet Wuhan citizens' demands. SL goes to people's life. Citizens are willing to carry out SL, proving the fashion of the era. Meanwhile, citizens are willing to do quiet and comfortable items with entertainment and healthcare in spring and autumn, like favorable and familiar relatives and family, stay for 1-3d, and carry out entertainment activity positively in Wuhan.

B. Suggestion: Administrative departments should highly value it and propose the corresponding policy for support, positively construct and perfect infrastructures and enlarge propaganda. Media spread relevant information to the masses, publicize health lifestyle, form the positive SL, formulate the corresponding laws and regulations and construct the good market order. Sports leisure should carry out the perfect facilities, maintain and standardize environment and service quality, and set up concept of honesty, abide by market morality, and gradually form the good custom on the basis of honesty and personal integrity. 


\section{ACKNOWLEDGMENT}

This work was financially supported by Humanities and social Scientific Research Guidance Project for Hubei Provincial Department of Education (16G163) fund.

\section{REFERENCES}

[1] Y Bian, Y Liao \& X.F. Zhang, the Development Philosophy of a Moderately Properous Society-Cognition on SL[J], Sichuan Sports Science, 2014(5): 8-11.

[2] T.N. Song, the SL Feature Study of Shenyang Citiznes under the Life Circle Theory[j], Science Vision, 2014(27): 25-26

[3] H. Y. Gao \& X.P Jiang, the Urban Residents' SL Opportunity Cognition of Demographic Charactersitic-Based on Zhejiang Residents[J], Zhejiang Sports Science, 2014(5): 1-6.

[4] X.M. Shao, the SL Feature Study in Chinese Urban Intermediate Stratum[J], Journal of Beijing Univrsity of Physicial Education, 2013(12): 23-29.

[5] G. H. Xie \& F. Lu, Cultural Analysis of SL[J], Journal of Chengdu Sports College, 2011(2): 51-53.

[6] J. Y. Yang, the Investigation Study on Shaoyang Urban Reisdents' SL and Influence Factors[J], Journal of Jingchu Institute of Technology, 2010, 10(11): 329-331

[7] G. H. Lu \& J. G. Li, Shanghai Citizens' Sports Behavior and Tendency Study[J], Journal of Xi'an Sports College, 2010, 10(11): 329-331.

[8] G.L Zhang and J.Q. Wang, Value on SL, [J], Journal of Tianjin Sports College, 2008(2): 51-53.

[9] W.T. Duan \& G. R. Jiang, Review of Theory of Planned Behavior[J], Mental Science Progress, 2008, 16(2): 51-53.

[10] Y. Xu, SL Behavior Intention Study of Changsha Citizens Based on Theory of Planned Behavior[D], Changshai: Hunan Normal University, 2010: 8-47. 